\title{
Trends in emergency contraception awareness among women and girls in 28 sub-Saharan countries
}

\author{
Oluwafemi Emmanuel Awopegba', Okechukwu Stephen Chukwudeh², Eyitayo Omolara Owolabi ${ }^{3}$ and \\ Anthony Idowu Ajayi ${ }^{4^{*}}$
}

\begin{abstract}
Background: Studies have shown that emergency contraception (EC) remains underutilised in preventing unintended pregnancy in sub-Saharan Africa (SSA). Small-scale surveys have attributed EC underutilisation to gaps in EC awareness among SSA women and girls. However, limited studies have explored trends in EC awareness in SSA. We address this gap by examining trends in EC awareness using data from 28 SSA countries. Our analysis was disaggregated by age distribution, place of residence, level of education, and wealth to show differences in EC awareness trend.

Methods: We analysed the Demographic and Health Surveys (DHS) data of 1,030,029 women aged 15 to 49 on emergency contraception awareness. EC awareness was defined as having ever heard of special pills to prevent pregnancy within 3 days after unprotected sexual intercourse. Frequencies and percentages were used to summarise trends in EC awareness between years 2000 and 2019.

Results: Overall, there was an upward shift in the level of EC awareness in all countries, except in Burkina Faso, Niger, Chad, and Ethiopia. While some countries recorded a significant upward trend in EC awareness, others recorded just a slight increase. Women in Kenya, Ghana, Gabon, and Cameroon had the highest upward shift in EC awareness. For example, only 28\% of women were aware of EC in Ghana in 2003, but in 2014, 64\% of women knew about EC, an increase of over 36 percentage points. Increase in EC awareness was starker among women aged 20-24 years, those who resided in urban areas, had higher education, and belong to the highest wealth quintile, than those aged 15-19, in rural areas, with no formal education and belonging to the lowest wealth quintile.

Conclusion: Our analysis shows that the level of EC awareness has increased substantially in most SSA countries. However, EC awareness still differs widely within and between SSA countries. Intervention to improve EC awareness should focus on women aged 15 to 19, those with no formal education, residing in rural areas, and within the lowest quintile, especially, in countries such as Chad, Niger, Burkina Faso, and Ethiopia where level of EC is low with lagging progress.
\end{abstract}

Keywords: Awareness, Emergency contraception, Sub-Saharan Africa, Trends, Unintended pregnancy

\footnotetext{
* Correspondence: ajayianthony@gmail.com

${ }^{4}$ Population Dynamics and Sexual and Reproductive Health, African

Population and Health Research Centre, APHRC Campus, Manga Close, Nairobi, Kenya

Full list of author information is available at the end of the article
}

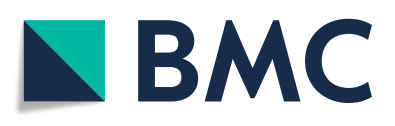

(- The Author(s). 2021 Open Access This article is licensed under a Creative Commons Attribution 4.0 International License, which permits use, sharing, adaptation, distribution and reproduction in any medium or format, as long as you give appropriate credit to the original author(s) and the source, provide a link to the Creative Commons licence, and indicate if changes were made. The images or other third party material in this article are included in the article's Creative Commons licence, unless indicated otherwise in a credit line to the material. If material is not included in the article's Creative Commons licence and your intended use is not permitted by statutory regulation or exceeds the permitted use, you will need to obtain permission directly from the copyright holder. To view a copy of this licence, visit http://creativecommons.org/licenses/by/4.0/. The Creative Commons Public Domain Dedication waiver (http://creativecommons.org/publicdomain/zero/1.0/) applies to the data made available in this article, unless otherwise stated in a credit line to the data. 


\section{Introduction}

Unplanned pregnancy and unsafe abortion are global social problems with severe socioeconomic, health, and demographic consequences. Despite conscientious efforts by public health experts, governments, and nongovernmental organizations, particularly since the 1994 International Conference on Population and Development (ICPD) in Cairo, the prevalence of unplanned pregnancies has barely declined [1]. A recent study shows that $49 \%$ of approximately 111 million pregnancies in Low and Middle-Income Countries (LMIC) are unplanned [2]. Notably, most pregnancies among adolescent girls are unplanned [3]. An estimated $42 \%$ of pregnancies in sub-Saharan Africa are unintended [2].

Unintended pregnancy is the main reason women and girls seek abortion. When women experience unintended pregnancy, some carry it to term while others seek abortion services. In SSA, about 37\% of women with unintended pregnancies terminate it. Due to restrictive abortion laws, most women (77\%) seek abortion from untrained persons or providers using non-recommended methods or both, resulting in complications, hospitalisation, disabilities, and deaths [4]. An estimated 6.2 million unsafe abortions occur each year in SSA, and 1.6 million women are treated for unsafe abortion-related complications [1]. The highest abortion-related deaths occur in SSA, and an estimated $50 \%$ of these deaths occur among young people [5].

Unintended pregnancy and unsafe abortion could be prevented with the use of contraceptives, especially emergency contraception (EC) [6,7]. However, the use of all contraceptive methods, particularly EC, remains low in most sub-Saharan Africa countries [8,9]. EC is effective in preventing pregnancy after sex [7]. Women who engage in unprotected sex voluntarily or involuntarily could still prevent unintended pregnancy if they are aware and can access emergency contraception. EC is available over the counter, without prescription, and has existed for more than four decades [9]. Its continued underutilisation suggests women and girls lack knowledge of its availability and benefits.

Previous studies-although primarily small-scale surveys and among young women-have shown that just over two in three young women are aware of $\mathrm{EC}$, and a little over half of them have the correct knowledge [10-18]. While many were not aware of emergency contraception, others lack knowledge of the correct EC pills and timing of use [10 11]. In addition, some women were misinformed about its side effects, erroneously linking it to infertility [11]. The lack of comprehensive sexuality education contributes to the awareness gaps on EC in sub-Saharan Africa. In general, there has been more attention to programmes promoting access to contraceptive information and services over the past two decades. However, the extent to which awareness of emergency contraception has increased among women and girls over the past 20 years (2000-2020) is unknown. Our study fills this gap by examining the trends of EC awareness in sub-Saharan Africa, using data from 28 countries. In addition, we examined the trends in EC awareness by age distribution, place of residence, level of education, and wealth.

\section{Methods and materials}

We analysed the Demographic and Health Surveys (DHS) data of 1,030,029 women aged 15 to 49 on emergency contraception awareness. The DHS is a nationally representative survey collected every 5 years across lowand middle-income countries. Given the objective of the study is to investigate trends of EC among women in SSA, we limited the scope to 28 countries in SSA that have two survey years information on EC awareness. Following the DHS guidelines, weightings were applied to obtain unbiased estimates. Bias can result in oversampled sub-populations by not using weights. A weighted sample of 1,030,151 women were considered. The list of countries, survey years, and analytic samples are provided in Table 1. Details on the data collection and sampling methodology used by the DHS can be accessed elsewhere [19].

\section{Study variables}

The main variable of interest is the awareness of EC method, measured as "Yes" if the respondent knows about $\mathrm{EC}$ and "No if the respondent does not know about EC. We disaggregated the women by 5 -year age groups, place of residence, wealth status, and education level to explore socio-demographic differences. Age groups comprised of ages 15 to 19 (adolescents), 20 to 24 (young adults) and 25 to 49 (adults). Residence was divided into "Rural" and "Urban" areas. Wealth status was assessed as an index of household assets and utilities, and categorized as "Poorest" "Poorer", "Middle", "Richer," and "Richest". Educational level was classified as "No formal education", "Primary", "Secondary and Higher".

\section{Statistical analysis}

To calculate the proportion of young women who knew of EC, we used descriptive statistics. The proportions for each SSA country are presented as percentages in a panel line graph format. Next, we present the association between EC and socio-demographic factors such as age, place of residence, wealth status, and education level, using Pearson's chi-square test. We carried out the analyses using STATA version 16.0.

\section{Ethical considerations}

This study only analysed de-identified publicly available data obtained in line with the highest ethical standard 
Table 1 Country and year sample

\begin{tabular}{|c|c|c|c|}
\hline Country & DHS Year & Unweighted Sample & Weighted Sample \\
\hline SSA & - & $1,030,029$ & $1,030,151$ \\
\hline \multicolumn{4}{|l|}{ Western } \\
\hline \multirow[t]{4}{*}{ Benin } & 2001 & 6210 & 6210 \\
\hline & 2006 & 17,676 & 17,681 \\
\hline & 2012 & 16,599 & 16,599 \\
\hline & 2018 & 15,928 & 15,928 \\
\hline \multirow[t]{2}{*}{ Burkina Faso } & 2003 & 12,472 & 12,471 \\
\hline & 2010 & 17,072 & 17,070 \\
\hline \multirow[t]{2}{*}{ Gambia } & 2011 & 10,202 & 10,209 \\
\hline & 2020 & 11,865 & 11,865 \\
\hline \multirow[t]{3}{*}{ Ghana } & 2003 & 5685 & 5688 \\
\hline & 2008 & 4907 & 4907 \\
\hline & 2014 & 9390 & 9393 \\
\hline \multirow[t]{3}{*}{ Guinea } & 2005 & 7925 & 7925 \\
\hline & 2012 & 9128 & 9124 \\
\hline & 2018 & 10,874 & 10,874 \\
\hline \multirow[t]{3}{*}{ Liberia } & 2007 & 7056 & 7061 \\
\hline & 2013 & 9210 & 9206 \\
\hline & 2019 & 8065 & 8065 \\
\hline \multirow[t]{4}{*}{ Mali } & 2001 & 12,828 & 12,829 \\
\hline & 2006 & 14,538 & 14,539 \\
\hline & 2012 & 10,424 & 10,424 \\
\hline & 2018 & 10,519 & 10,519 \\
\hline \multirow[t]{2}{*}{ Niger } & 2006 & 9201 & 9205 \\
\hline & 2012 & 11,138 & 11,137 \\
\hline \multirow[t]{4}{*}{ Nigeria } & 2003 & 7590 & 7581 \\
\hline & 2008 & 33,243 & 33,240 \\
\hline & 2013 & 38,823 & 38,820 \\
\hline & 2018 & 41,821 & 41,821 \\
\hline \multirow[t]{4}{*}{ Senegal } & 2005 & 14,570 & 14,570 \\
\hline & 2011 & 15,688 & 15,688 \\
\hline & 2014 & 8488 & 8488 \\
\hline & 2019 & 8649 & 8649 \\
\hline \multirow[t]{3}{*}{ Sierra Leone } & 2008 & 7360 & 7359 \\
\hline & 2013 & 16,630 & 16,627 \\
\hline & 2019 & 15,574 & 15,574 \\
\hline \multicolumn{4}{|l|}{ Central } \\
\hline \multirow[t]{2}{*}{ Burundi } & 2010 & 9379 & 9376 \\
\hline & 2016 & 17,269 & 17,269 \\
\hline \multirow[t]{3}{*}{ Cameroon } & 2004 & 10,637 & 10,635 \\
\hline & 2011 & 15,390 & 15,386 \\
\hline & 2018 & 13,527 & 13,616 \\
\hline \multirow[t]{2}{*}{ Chad } & 2004 & 6084 & 6085 \\
\hline & 2015 & 17,661 & 17,663 \\
\hline
\end{tabular}


Table 1 Country and year sample (Continued)

\begin{tabular}{|c|c|c|c|}
\hline Country & DHS Year & Unweighted Sample & Weighted Sample \\
\hline \multirow[t]{2}{*}{ Congo } & 2005 & 7003 & 39 \\
\hline & 2011 & 10,790 & 100 \\
\hline \multirow[t]{2}{*}{ Congo DRC } & 2007 & 9969 & 9966 \\
\hline & 2013 & 18,779 & 18,793 \\
\hline \multirow[t]{2}{*}{ Gabon } & 2001 & 6167 & 6170 \\
\hline & 2012 & 8356 & 8358 \\
\hline \multicolumn{4}{|l|}{ Eastern } \\
\hline \multirow[t]{2}{*}{ Ethiopia } & 2011 & 16,497 & 16,507 \\
\hline & 2016 & 15,683 & 15,683 \\
\hline \multirow[t]{3}{*}{ Kenya } & 2003 & 8189 & 8189 \\
\hline & 2009 & 8442 & 8443 \\
\hline & 2014 & 31,072 & 31,075 \\
\hline \multirow[t]{2}{*}{ Madagascar } & 2004 & 7947 & 7949 \\
\hline & 2009 & 17,364 & 17,368 \\
\hline \multirow[t]{4}{*}{ Rwanda } & 2000 & 10,412 & 10,410 \\
\hline & 2005 & 11,302 & 11,302 \\
\hline & 2010 & 13,664 & 13,664 \\
\hline & 2015 & 13,489 & 13,486 \\
\hline \multirow[t]{3}{*}{ Tanzania } & 2004 & 10,317 & 10,318 \\
\hline & 2010 & 10,135 & 10,135 \\
\hline & 2015 & 13,265 & 13,265 \\
\hline \multirow[t]{3}{*}{ Uganda } & 2006 & 8524 & 8525 \\
\hline & 2011 & 8669 & 8671 \\
\hline & 2016 & 18,506 & 18,506 \\
\hline \multicolumn{4}{|l|}{ Southern } \\
\hline \multirow[t]{3}{*}{ Lesotho } & 2004 & 7094 & 7095 \\
\hline & 2009 & 7624 & 7624 \\
\hline & 2014 & 6621 & 6621 \\
\hline \multirow[t]{4}{*}{ Malawi } & 2000 & 13,189 & 13,184 \\
\hline & 2004 & 11,689 & 11,685 \\
\hline & 2010 & 23,003 & 23,006 \\
\hline & 2015 & 24,562 & 24,562 \\
\hline \multirow[t]{3}{*}{ Namibia } & 2000 & 6745 & 6748 \\
\hline & 2007 & 9784 & 9785 \\
\hline & 2013 & 9164 & 9168 \\
\hline \multirow[t]{4}{*}{ Zambia } & 2002 & 7644 & 7643 \\
\hline & 2007 & 7146 & 7146 \\
\hline & 2013 & 16,325 & 16,330 \\
\hline & 2018 & 13,683 & 13,683 \\
\hline \multirow[t]{4}{*}{ Zimbabwe } & 1999 & 5899 & 5901 \\
\hline & 2005 & 8895 & 8895 \\
\hline & 2010 & 9171 & 9171 \\
\hline & 2015 & 9955 & 9955 \\
\hline
\end{tabular}


for conducting human subject research; therefore, we did not seek ethical approval. The DHS surveys are conducted after approval of ethical review bodies and authorization by the country of the study. De-identified datasets are freely available on the DHS website (https:// dhsprogram.com/data/available-datasets.cfm).

\section{Results}

\section{Trends in EC awareness within and between countries}

Figure 1 depicts the trends in women's awareness of emergency contraception (EC) in 28 SSA countries. While over half of women in Ghana (64\%), Kenya (59\%), and Cameroon (53\%) were aware of EC, only one in ten women knew of EC in Chad (5.8\%), Niger (4.4\%), Madagascar (10.1\%) and Burkina Faso (11.6\%). Overall, there was an upward shift in the level of EC awareness in all countries, except in Burkina Faso, Niger, Chad, and Ethiopia. While some countries recorded a significant upward trend in EC awareness, others recorded just a slight increase. Women in Kenya, Ghana, Gabon, and Cameroon had the highest upward shift in EC awareness. For example, only $28 \%$ of women were aware of
EC in Ghana in 2003, but in 2014, 64\% of women knew about EC, an increase of over 36 percentage points.

The level of awareness of EC is lowest among adolescent girls (15-19 years) in all countries studied. In Ghana, for example, the difference in EC awareness between adolescent girls (15-19 years) and young adults (20-24 years) was approximately 27 percentage points in 2014. We observed an upward trend in EC awareness in all age groups in most countries studied. However, it appears that the upward trend is steeper in the age group $20-24$ years than in other age categories.

\section{Urban and rural trends}

Figure 2 illustrates the proportion of women of reproductive age who knew about EC by place of residence. EC awareness was significantly higher among women residing in urban areas than those in rural areas in all countries studied. While EC awareness has increased in both rural and urban areas in most countries, the upward trend is far steeper for urban areas than in rural areas. For example, EC awareness rose by 40 percentage points (from $32.8 \%$ in 2004 to $73.8 \%$ in 2014) in urban areas in Ghana compared to $20 \%$ in rural areas (from

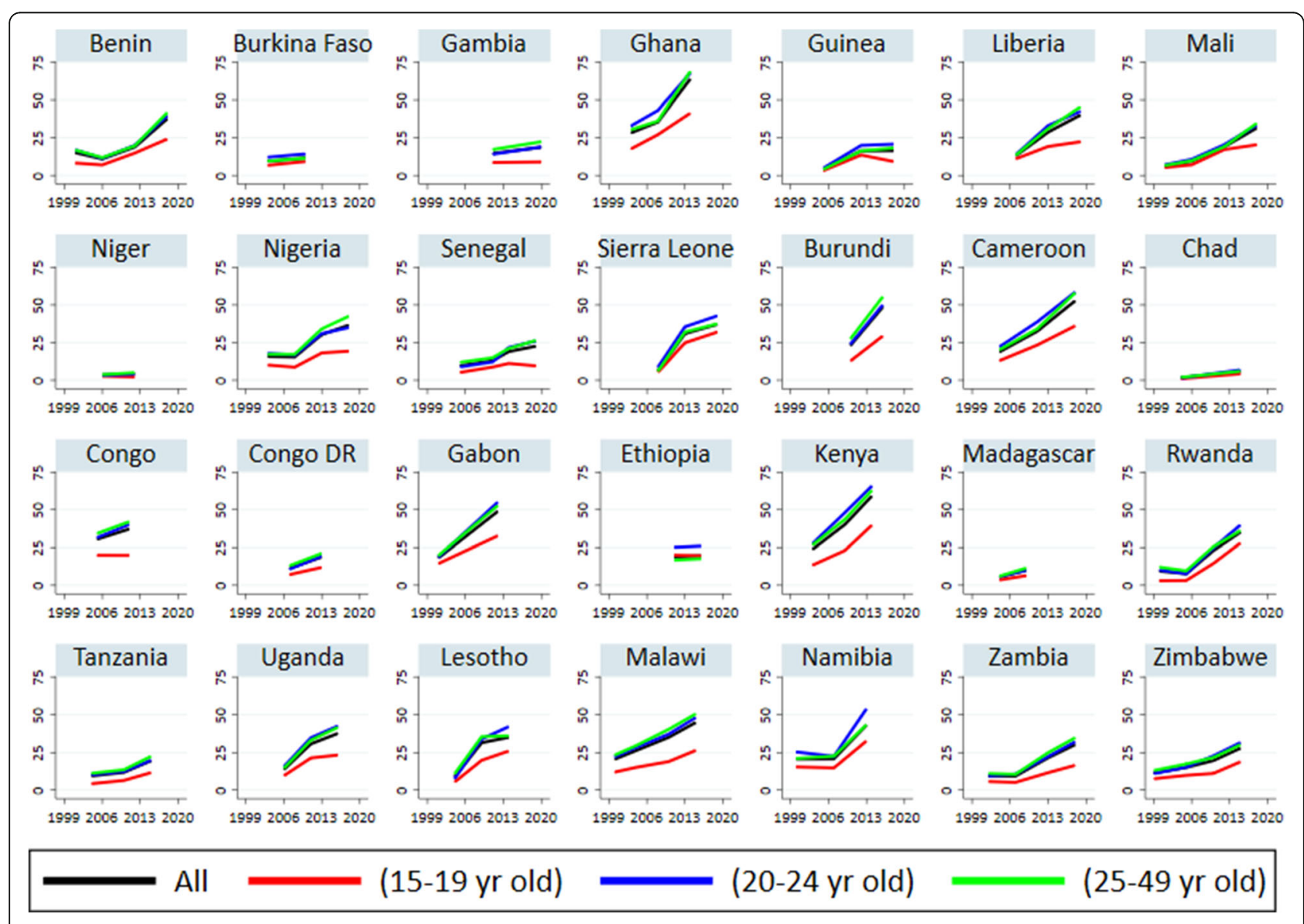

Fig. 1 Trends in EC awareness by age categories (15 to 19, 20 to 24 and 25 to 49 year) in SSA between 1999 and 2019 


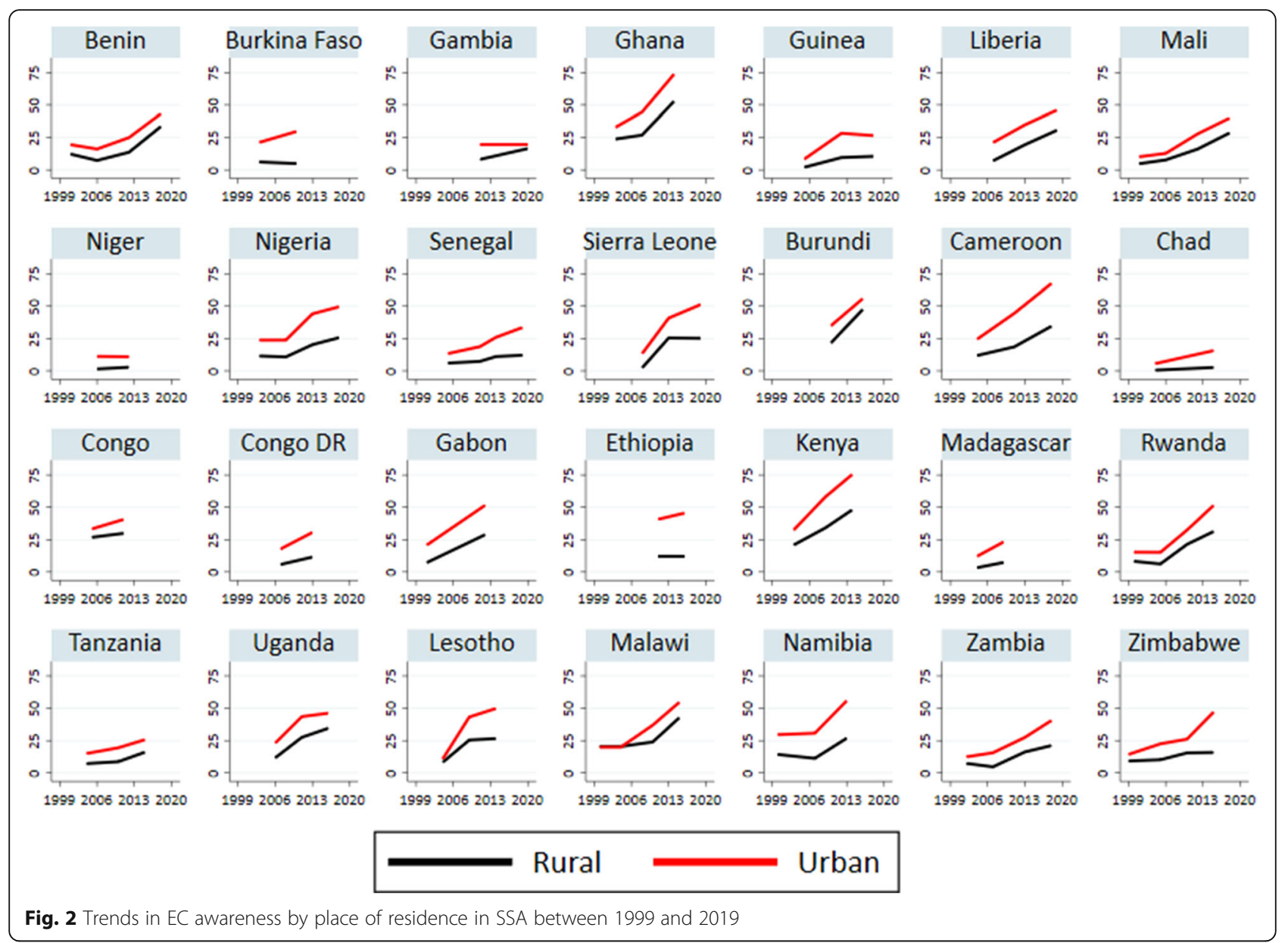

$23.8 \%$ in 2004 to $52.9 \%$ in 2014). Similarly, EC awareness rose by $43 \%$ in Cameroon and Kenya in urban areas compared to $13 \%$ in rural areas in Cameroon and $28 \%$ in rural Kenya. However, in countries like Niger, Ethiopia, Chad, and Burkina Faso, the level of awareness of EC remains unchanged among rural women.

\section{Trends by level of education}

Trend in the proportion of women who knew about EC by their level of education is depicted in Fig. 3. The magnitude of variation in EC awareness by levels of education is stark. While four in five women with higher education were aware of EC in 15 of the 28 countries studied, only about one in ten women with no education knew of EC in 15 countries, one in five in three countries (Cameroon, Kenya, and Gabon), two in five in two countries (Ghana and Malawi), and one in three in Benin and Liberia. There was an upward trend in EC awareness for all education categories, except in nine countries (Burkina Faso, Niger, Congo, Ethiopia, Congo Dr., Chad, Madagascar, Zimbabwe, and Lesotho), where EC awareness remained unchanged among women with no formal education. The increase in EC awareness is starker among women with higher education than for women with other educational levels.

\section{Trends by wealth index}

Figure 4 depicts trends in EC awareness by wealth quintiles in 28 sub-Saharan African countries. Generally, EC awareness differs substantially by wealth status in all countries studied. Women from the poorest households were the least aware of EC than women from the richest households. For example, more than one in two women in the richest wealth quintile knew of EC in 14 of the 28 countries studied relative to only one in ten in 11 countries. Also, EC awareness improved more substantially among women in the wealthiest quintile than among women in the lowest wealth quintile. For example, EC awareness increased among women in the richest wealth quintile by $50 \%$ in Ghana, $43 \%$ in Sierra Leone, $47 \%$ in Cameroon, $50 \%$ in Kenya, and $47 \%$ in Lesotho, relative to only $9 \%$ among women in the poorest households in Ghana, 20\% in Sierra Leone, 14\% in Cameroon, 15\% in Kenya, and $4 \%$ in Lesotho. 


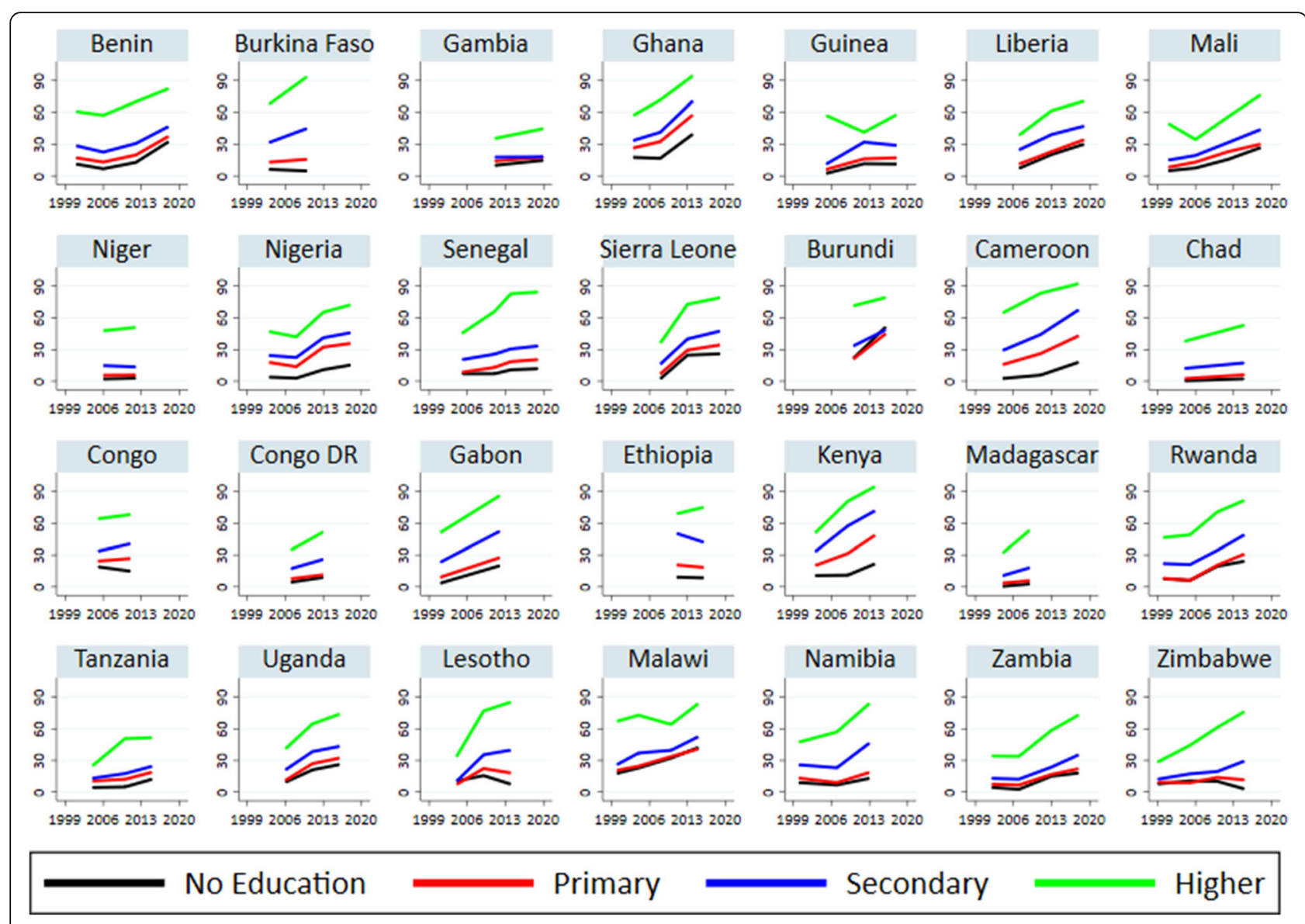

Fig. 3 Trends in EC awareness by education level in 28 sub-Saharan countries between 1999 and 2019

\section{Discussion}

Emergency contraception can prevent unplanned pregnancy after unprotected sex or rape, but gaps exist in women's awareness of this method. We conducted a trend analysis of women's awareness of EC using the DHS data of 28 SSA countries. Our analyses show that EC awareness significantly increased in most countries between the years 2000 and 2019 . However, a few countries recorded no progress. The increase in EC awareness is not surprising given the increased focus on improving women's knowledge of contraceptives in SSA [20] since the 1994 International Conference on Population and Development. Many development partners and governments have implemented programmes to boost women's knowledge and use of contraceptives. What is surprising is the lack of progress in Chad, Niger, Burkina Faso, and Ethiopia despite efforts to improve women's EC awareness in these countries. It is plausible the family planning programmes in these countries have not prioritised emergency contraceptives.

One notable finding of this study is that increase in EC awareness remain uneven within countries. While
EC awareness has increased substantially among young women aged 20 to 24 , a slight improvement was recorded among girls aged 15-19 in most countries. Girls aged 15-19 have relatively low awareness of EC compared to young women aged 20-24 in all countries studied. The differences could be explained by better exposure of young women (aged 20-24) to information sources relative to adolescent girls [21-23]. In most SSA countries, sexuality education is abstinence-based and HIV prevention-focused, neglecting aspects like contraceptive methods, including EC [24]. However, as young people initiate sex, their need for contraceptive information would increase. Because of the higher prevalence of sexual activities among females aged 2024 years than $15-19$ years old, they will likely source for information on the subject more than the adolescent girls. Health care visit for sexual and reproductive health services is higher among young women aged 20-24 years than adolescent girls [25], thus, increasing their chances of learning about EC. Improvement in EC awareness among adolescent girls would remain slow, except they are deliberately targeted with such information through sexuality education programmes. 


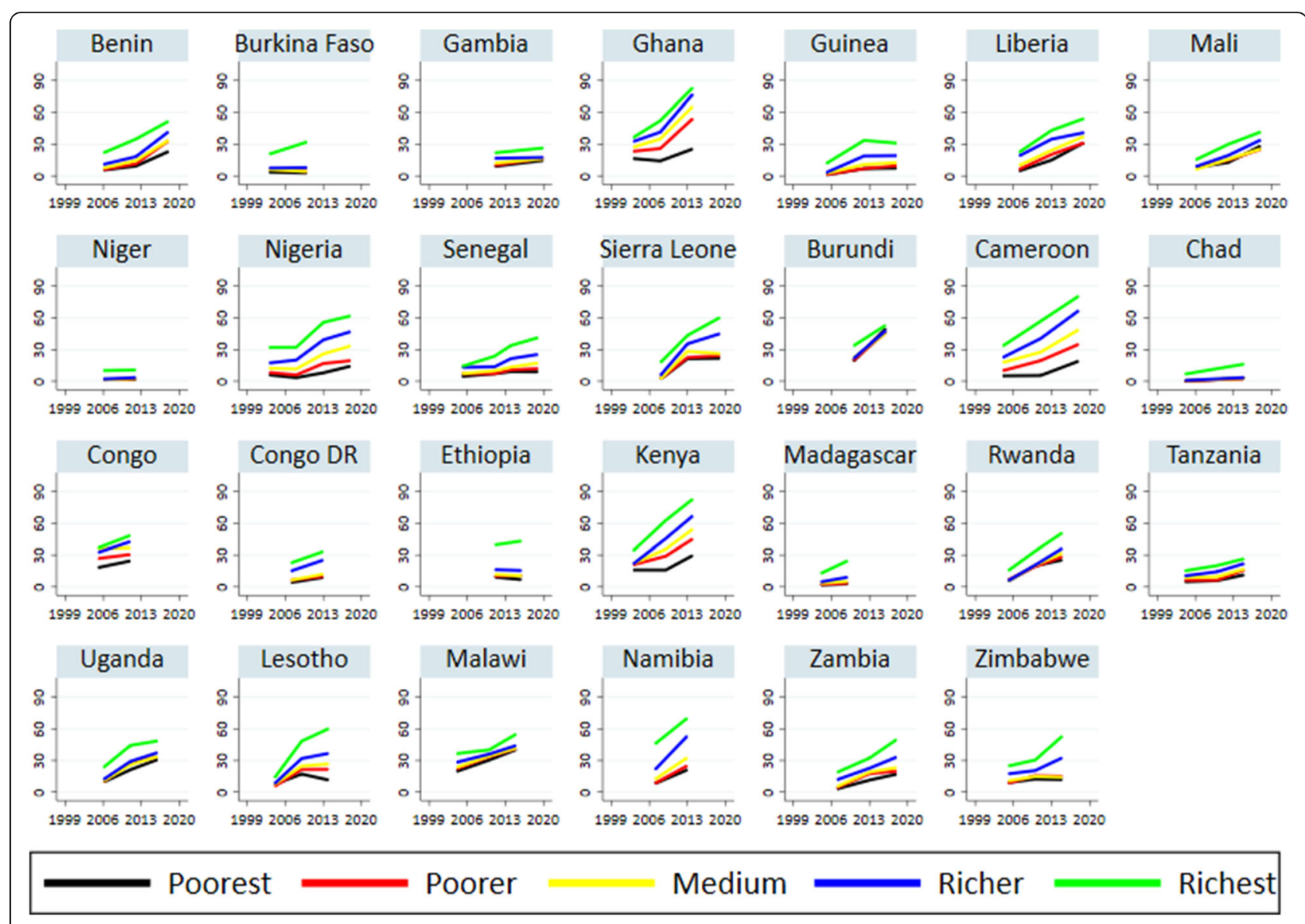

Fig. 4 Trends in EC awareness by wealth status in 28 sub-Saharan countries: 1999 to 2019

We also found huge rural and urban differences in EC awareness in most countries. Increase in EC awareness was substantial in urban areas than in rural areas in all countries studied. This finding is expected given that women in urban areas have better access to the Internet, media platforms, and health providers than women in rural areas in most SSA countries [21, 23, 25]. Access to the Internet grew rapidly between 2000 and 2019 in SSA [26], and this could have helped many women access EC information without needing to consult health providers. In several SSA countries, access to electricity, the Internet, and smartphones in rural areas remain limited compared to urban areas. As a result, women in rural areas are less likely to learn about EC through the Internet. Another plausible reason for the rural and urban differences in EC awareness progress is that family planning programmes targeting improving access to information and services are implemented in urban areas than rural areas. Social marketing of family planning methods is widely available in urban areas than rural areas [27], which could explain the wide rural and urban differences in EC awareness.
We also observed a stark increase in EC awareness among women with higher education than those with lower educational levels in all countries. Similar finding was observed when we stratified our analysis by wealth status. Much of the increase in EC awareness in SSA occurred among women with a higher level of education and those in the highest wealth quintile. This is not surprising given that they tend to have access to information from multiple sources, including the Internet and through their social networks, compared to less educated women and those in the lowest wealth quintile. However, the slow increase in EC awareness among lesseducated women and those in the lowest wealth quintile is concerning, given the importance of the knowledge of unplanned pregnancy prevention. It means they may become susceptible to unintended pregnancy and potentially carry such an unwanted pregnancy to term because abortion services are restricted in most SSA settings. In addition, low EC awareness among less-educated women is one reason for the underutilisation of EC and its limited effect in significantly reducing unintended pregnancy in SSA. 


\section{Study strengths and limitations}

The definition of EC as special pills women can use to prevent pregnancy is a limitation of our study, given that studies have shown that a few women considered nonEC drugs and concoctions as EC [10,11]. This limitation could have slightly inflated the proportion of women that were aware of the correct EC methods. However, our use of large datasets from 28 SSA countries is important strength of this study, allowing us to report robust findings on differing EC awareness within and between SSA countries.

\section{Conclusion}

Our analysis shows that the level of EC awareness has increased substantially in most SSA countries. However, EC awareness still differs significantly within and between SSA countries. In addition, increase in EC awareness was starker among women aged 20-24 years, who resided in urban areas, had higher education, and belonged to the highest wealth quintile. Intervention to improve EC awareness should focus on countries like Chad, Niger, Burkina Faso, and Ethiopia, where awareness remained low and minimal progress was recorded.

\section{Abbreviations}

EC: Emergency contraception; SSA: Sub-Saharan Africa; DHS: Demographic and Health Surveys; LMICs: Low-and middle-income countries; HIV: Human Immunodeficiency Virus

\section{Supplementary Information}

The online version contains supplementary material available at https://doi. org/10.1186/s12889-021-12067-y.

Additional file 1: Table S1. Prevalence of EC and Association between EC and Socio-Demographics of women in 28 sub-Saharan countries between 1999 and 2019

\section{Acknowledgments}

The authors acknowledge the African Population and Health Research Center for funding AIA time during which he worked on this article.

\section{Authors' contributions}

The study was conceptualised by AIA. Data analysis and interpretation were conducted by OEA and AIA. SC made the initial manuscript draft. AIA and EOO made substantial contributions to the manuscript review. All authors revised and approved the final version of the manuscript.

\section{Funding}

None.

\section{Availability of data and materials}

The DHS data utilised for this study is publicly available via https://www. dhsprogram.com/data/available-datasets.cfm

\section{Declarations}

\section{Ethics approval and consent to participate}

This study only analysed de-identified publicly available data obtained in line with the highest ethical standard for conducting human subject research; therefore, we did not seek ethical approval. The DHS surveys are conducted after approval of ethical review bodies and authorization by the country of the study. De-identified datasets are freely available on the DHS website (https://dhsprogram.com/data/available-datasets.cfm).

\section{Consent for publication}

Not Applicable.

\section{Competing interests}

The authors declare no conflict of interest

\section{Author details}

${ }^{1}$ Economics and Business Policy Department, Nigerian Institute of Social and Economic Research, Ibadan, Nigeria. ${ }^{2}$ Department of Criminology and Security Studies, Faculty of Social Sciences, Federal University, Oye-Ekiti, Nigeria. ${ }^{3}$ Centre for Global Surgery, Department of Global Health, Stellenbosch University, Cape Town, South Africa. ${ }^{4}$ Population Dynamics and Sexual and Reproductive Health, African Population and Health Research Centre, APHRC Campus, Manga Close, Nairobi, Kenya.

Received: 1 September 2021 Accepted: 21 October 2021

Published online: 03 November 2021

\section{References}

1. Sedgh G, Singh S, Hussain R. Intended and unintended pregnancies worldwide in 2012 and recent trends. Stud Fam Plan. 2014;45(3):301-14 https://doi.org/10.1111/j.1728-4465.2014.00393.x.

2. Sully E, Biddlecom A, Darroch JE, et al. Adding it up: investing in sexual and reproductive health 2019 . 2020.

3. Ajayi Al, Odunga SA, Oduor C, Ouedraogo R, Ushie BA, Wado YD. "I was tricked": understanding reasons for unintended pregnancy among sexually active adolescent girls. Reprod Health. 2021;18(1):1-11. https://doi.org/10.11 86/s12978-021-01078-y.

4. Singh S, Remez L, Sedgh G, et al. Abortion worldwide 2017: uneven Progress and unequal access. New York: Guttmacher Institute; 2018.

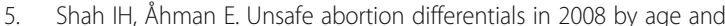
developing country region: high burden among young women. Reprod Health Matters. 2012;20(39):169-73. https://doi.org/10.1016/S0968-8080(12 39598-0.

6. Trussell J, Raymond EG, Cleland K. Emergency contraception: a last chance to prevent unintended pregnancy. Contemp Read Law Soc Justice. 2014;6:7.

7. Trussell J, Rodríguez G, Ellertson C. Updated estimates of the effectiveness of the Yuzpe regimen of emergency contraception. Contraception. 1999; 59(3):147-51. https://doi.org/10.1016/S0010-7824(99)00018-9.

8. Ba DM, Ssentongo P, Agbese E, Kjerulff KH. Prevalence and predictors of contraceptive use among women of reproductive age in 17 sub-Saharan African countries: a large population-based study. Sex Reprod Healthc. 2019; 21:26-32. https://doi.org/10.1016/j.srhc.2019.06.002.

9. Ajayi Al, Adeniyi OV, WJBph A. Use of traditional and modern contraceptives among childbearing women: findings from a mixed methods study in two southwestern Nigerian states. 2018;18(1):604. https:// doi.org/10.1186/s12889-018-5522-6.

10. Ajayi Al, Nwokocha EE, Adeniyi OV, ter Goon D, Akpan W. Unplanned pregnancy-risks and use of emergency contraception: a survey of two Nigerian universities. BMC Health Serv Res. 2017;17(1):382. https://doi.org/1 0.1186/s12913-017-2328-7.

11. Ajayi Al, Nwokocha EE, Akpan W, Adeniyi OV. Use of non-emergency contraceptive pills and concoctions as emergency contraception among Nigerian University students: results of a qualitative study. BMC Public Health. 2016;16(1):1046. https://doi.org/10.1186/s12889-016-3707-4.

12. Karim SI, Irfan F, Al Rowais N, et al. Emergency contraception: awareness, attitudes and barriers of Saudi Arabian women. Pak J Med Sci. 2015;31(6): 1500-5. https://doi.org/10.12669/pjms.316.8127.

13. Lukhaimane TA, Adam Y. Women's willingness to use emergency contraception: experience at Chris Hani Baragwanath academic hospital, Johannesburg, South Africa: forum-healthcare delivery. S Afr Med J. 2015; 105(4):266-7. https://doi.org/10.7196/SAMJ.9411.

14. Maharaj $P$, Rogan M. Missing opportunities for preventing unwanted pregnancy: a qualitative study of emergency contraception. BMJ Sex Reprod Health. 2011;37(2):89-96

15. Myer L, Mlobeli R, Cooper D, Smit J, Morroni C. Knowledge and use of emergency contraception among women in the Western cape province of 
South Africa: a cross-sectional study. BMC Womens Health. 2007;7(1):1-7. https://doi.org/10.1186/1472-6874-7-14.

16. Palermo T, Bleck J, Westley E. Knowledge and use of emergency contraception: a multicountry analysis. Int Perspect Sex Reprod Health. 2014; 40(2):79-86. https://doi.org/10.1363/4007914.

17. Rokicki S, Merten S. The context of emergency contraception use among young unmarried women in Accra, Ghana: a qualitative study. Reprod Health. 2018;15(1):1-10. https://doi.org/10.1186/s12978-018-0656-7.

18. Thompson J, Undie C-C, Askew I. Access to emergency contraception and safe abortion services for survivors of rape: a review of policies, programmes and country experiences in sub-Saharan Africa; 2014.

19. Corsi DJ, Neuman M, Finlay JE, Subramanian S. Demographic and health surveys: a profile. Int J Epidemiol. 2012;41(6):1602-13. https://doi.org/10.1 093/ije/dys 184.

20. Cleland JG, Ndugwa RP, Zulu EM. Family planning in sub-Saharan Africa: progress or stagnation? Bull World Health Organ. 2011;89(2):137-43. https:// doi.org/10.2471/BLT.10.077925.

21. Marron O, Thomas G, Burdon Bailey JL, Mayer D, Grossman PO, Lohr F, et al. Factors associated with mobile phone ownership and potential use for rabies vaccination campaigns in southern Malawi. Infect Dis Poverty. 2020; 9(1):1-11. https://doi.org/10.1186/s40249-020-00677-4.

22. Duggan M, Brenner J. The demographics of social media users, 2012. Washington, DC: Pew research Center's internet \& American life project; 2013.

23. Doyle AM, Bandason T, Dauya E, McHugh G, Grundy C, Dringus S, et al. Mobile phone access and implications for digital health interventions among adolescents and young adults in Zimbabwe: cross-sectional survey. JMIR mHealth and uHealth. 2021;9(1):e21244. https://doi.org/10.2196/21244.

24. Elia JP, Eliason MJ. Dangerous omissions: abstinence-only-until-marriage school-based sexuality education and the betrayal of LGBTQ youth. Am J Sex Educ. 2010;5(1):17-35. https://doi.org/10.1080/15546121003748848

25. Owolabi OO, Wong KL, Dennis ML, et al. Comparing the use and content of antenatal care in adolescent and older first-time mothers in 13 countries of West Africa: a cross-sectional analysis of demographic and health surveys. Lancet Child Adolesc Health. 2017;1 (3):203-12. https://doi.org/10.1016/S23 52-4642(17)30025-1.

26. Chang YS, Jeon S, Shamba K. Speed of catch-up and digital divide: convergence analysis of Mobile cellular, internet, and fixed broadband for 44 African countries. J Glob Inf Technol Manag. 2020;23(3):217-34. https:// doi.org/10.1080/1097198X.2020.1792231.

27. White JS, Speizer IS. Can family planning outreach bridge the urban-rural divide in Zambia? BMC Health Serv Res. 2007;7(1):1-9. https://doi.org/10.11 86/1472-6963-7-143

\section{Publisher's Note}

Springer Nature remains neutral with regard to jurisdictional claims in published maps and institutional affiliations.

Ready to submit your research? Choose BMC and benefit from:

- fast, convenient online submission

- thorough peer review by experienced researchers in your field

- rapid publication on acceptance

- support for research data, including large and complex data types

- gold Open Access which fosters wider collaboration and increased citations

- maximum visibility for your research: over $100 \mathrm{M}$ website views per year

At $\mathrm{BMC}$, research is always in progress.

Learn more biomedcentral.com/submissions 